\title{
Pulmonary Tuberculosis in HIV/AIDS Patients Attending Art Clinic in Bududa General Hospital, Bududa District, Uganda
}

\author{
Kalyetsi Rogers ${ }^{*}$, Nafungo Gertrude ${ }^{2}$, Muwanguzi Enoch ${ }^{1}$ \\ ${ }^{1}$ Department of Medical Laboratory Sciences, Faculty of Medicine, Mbarara University of Science and Technology, Mbarara, \\ Uganda \\ ${ }^{2}$ Laboratory Department, Bududa General Hospital, Mbale, Uganda \\ Email: `rkalyetsi@must.ac.ug, `kalyetsirogersm@gmail.com, nafungogertrude1@gmail.com, menoch@must.ac.ug
}

How to cite this paper: Rogers, K., Gertrude, N. and Enoch, M. (2019) Pulmonary Tuberculosis in HIV/AIDS Patients Attending Art Clinic in Bududa General Hospital, Bududa District, Uganda. Journal of Tuberculosis Research, 7, 135-142. https://doi.org/10.4236/jtr.2019.73013

Received: June 26, 2019

Accepted: September 7, 2019

Published: September 10, 2019

Copyright $\odot 2019$ by author(s) and Scientific Research Publishing Inc. This work is licensed under the Creative Commons Attribution International License (CC BY 4.0). http://creativecommons.org/licenses/by/4.0/

\section{Open Access}

\begin{abstract}
Background: Tuberculosis disease affects survival among HIV co-infected patients on antiretroviral therapy. Prevalence of pulmonary tuberculosis in western Uganda is $15.3 \%$ and $7.2 \%$ in Tororo, Eastern Uganda. A study in Kampala revealed Tuberculosis prevalence among immuno-incompetent group at 10\%. To assess the prevalence of Pulmonary Tuberculosis (PTB) infection in HIV/AIDS patients attending ART clinic in Bududa general hospital, Bududa district, a hospital-based, cross-sectional study was carried out. Methods and materials: Two hundred thirty eight (238) HIV/AIDS positive patients attending ART clinic were recruited using consecutive simple non-probability sampling on consenting. Data collection guide was used to capture the socio-demographic information from study participants and two sputum samples (spot and early morning samples) were obtained from each participant, and processed using Hot Ziehl Neelsen for Tubercle Bacilli. Data collected was entered into MS Excel spreadsheets and Statistical Package of Social Sciences was used for descriptive data analysis and outputs in form of percentages, figures and tables presented. Results: Out of 238 study participants recruited, 14/238 were positive for Acid Fast Bacilli (AFB); giving a prevalence of pulmonary tuberculosis at 5.9\% (14/238) and the most affected age group was between 26 - 35 years with the prevalence of $3.4 \%$. More females (65.6\%) participated in the study than males (34.4\%). Conclusion: Tuberculosis remains a health challenge in HIV/AIDS positive people in $\mathrm{Bu}-$ duda district and there is need for early screening of all HIV patients for TB as part of their routine and intensification to follow up TB positive patients. We recommend large-scale studies on the trends in TB/HIV co-infection and associated factors should be carried out in this area. In addition, we recom-
\end{abstract}


mend intensification of public awareness campaign about TB infection in relation to its transmission, prevention and control.

\section{Keywords}

Pulmonary Tuberculosis, HIV Infection, Prevalence, HIV/TB Co-Infection

\section{Introduction}

Tuberculosis disease affects survival among HIV co-infected patients on antiretroviral therapy. The risk of developing tuberculosis is estimated to be between 16 - 27 times greater in people living with HIV than among those without HIV infection. In Uganda, with national HIV prevalence of 7.3\%, 45,546 TB patients were diagnosed in the year 2010 of which 54\% were HIV-infected [1] [2].

Uganda is one of the high burden twenty two countries in Sub-Sahara Africa that contributes $80 \%$ of the world's tuberculosis burden [3]. A number of studies in Uganda indicate that TB is the leading cause of death in HIV patients, many of whom die before TB is confirmed by laboratory methods [4] [5]. Study in Kampala among one of the immuno-incompetent group gave prevalence of $10 \%$ [6]. The prevalence of tuberculosis in western Uganda is $15.3 \%$ [2] and $7.2 \%$ in Tororo, Eastern Uganda [7] Tuberculosis prevalence is exacerbated with the increasing incidences of drug resistance and delayed diagnosis [8]. Accurate estimates of prevalence are important for public policy and planning to prevent disease spread yet, the magnitude of TB disease on mortality is poorly understood in Bududa Hospital. As such, we sought to determine the Prevalence of Pulmonary Tuberculosis in HIV/AIDS patients attending ART clinic at Bududa general Hospital, Bududa district in Eastern Uganda.

\section{Methods and Materials}

\subsection{Study Population}

The study population involved HIV/AIDs positive patients (male and female) who attended ART clinic during the study period recruited on consenting.

\subsection{Study Site Setting}

The study was carried out at Bududa district general Hospital ART clinic in Bududa District, Eastern Uganda.

\subsection{Study Design}

A cross sectional study was carried out to determine the prevalence of TB in HIV/AIDS patients attending ART clinic at Bududa general hospital.

\subsection{Sampling Method}

Consecutive non-probability sampling technique was used to recruit 238 HIV/AIDs 
positive patients who attended ART clinic during the study period; the sample size was determined [9]; with TB prevalence at 15 at $95 \%$ confidence interval and 0.05 maximum variation was tolerated.

\subsection{Data and Specimen Collection Technique}

Data collection tool was used to capture socio-demographic characteristics from study participants. Sputum samples (spot and early morning samples) were obtained from each participant, direct sputum smears were made by selecting the cheesy like, necrotic particles (abnormal portions), smears were air dried, fixed using absolute methanol for two minutes and then stained by using hot Ziehl-Neelsen technique [9] and the examined using light microscopy for presence or absence of Acid Fast Bacilli and findings recorded.

\subsection{Data Analysis}

Data collected was entered into MS Excel spreadsheets; Cross-checking and data cleaning was done. Statistical Package of Social Sciences was used for descriptive data analysis and outputs in form of charts, and tables presented. The prevalence was calculated as the number of individuals with TB divided by the total number of participants $(n=238)$ multiplied by 100 using $95 \%$ confidence interval.

\subsection{Ethical Consideration}

Clearance was sought from Faculty Research Ethics Committee (FREC) of Mbarara University of Science and Technology, Oral and formal informed consent was obtained from the patients prior to enrolment and confidentiality was assured.

\section{Results}

A total of 238 HIV/AIDS patients were recruited and screened for pulmonary TB using sputum samples. The prevalence was found to be $5.9 \%$ and age-related prevalence was highest in 26 - 35 age group and majority of participants were females contributing $65.6 \%(156 / 238)$ of the sample size.

\subsection{Baseline Characteristics of the Study Participants}

Data collection guide was used to capture baseline characteristics (Age and Gender) of study participants. Of the 238 study participants who participated in the study, females were $65.6 \%(156 / 238)$ and males were $34.4 \%(82 / 238)$ as shown in Table 1 below.

\subsection{Laboratory Findings}

Sputum samples were processed and examined for the presence or absence of AFB and the findings are shown in Table 2 below.

Of the 238 study participants who were sampled, 14/238 had Acid fast bacilli (positive cases) and 224/238 were negative for pulmonary tuberculosis giving a prevalence of $5.9 \%$. 
Table 1. Base line characteristics of study participants.

\begin{tabular}{cccc}
\hline & Variable & Frequency $(\mathrm{n}=\mathbf{2 3 8})$ & Percentage (\%) \\
\hline \multirow{3}{*}{ Gender } & Female & 156 & 65.6 \\
& Male & 82 & 34.4 \\
& $0-15$ & 28 & 12 \\
Age group & $16-25$ & 26 & 11 \\
& $26-35$ & 58 & 24 \\
& $36-45$ & 76 & 32 \\
& $46-$ above & 50 & 21 \\
\hline
\end{tabular}

Table 2. Distribution of pulmonary tuberculosis in relation to gender.

\begin{tabular}{|c|c|c|c|c|}
\hline & & \multicolumn{2}{|c|}{ Lab-results } & \multirow{2}{*}{ Tota } \\
\hline & & Negative & Positive & \\
\hline \multirow{2}{*}{ Gender } & Female & 146 & 10 & 156 \\
\hline & Male & 78 & 4 & 82 \\
\hline \multicolumn{2}{|c|}{ Total } & 124 & 14 & 238 \\
\hline
\end{tabular}

\subsection{Distribution of TB Cases by Age Groups of Participant}

Study participants were categorized into five age groups to establish distribution of cases by age brackets (Figure 1).

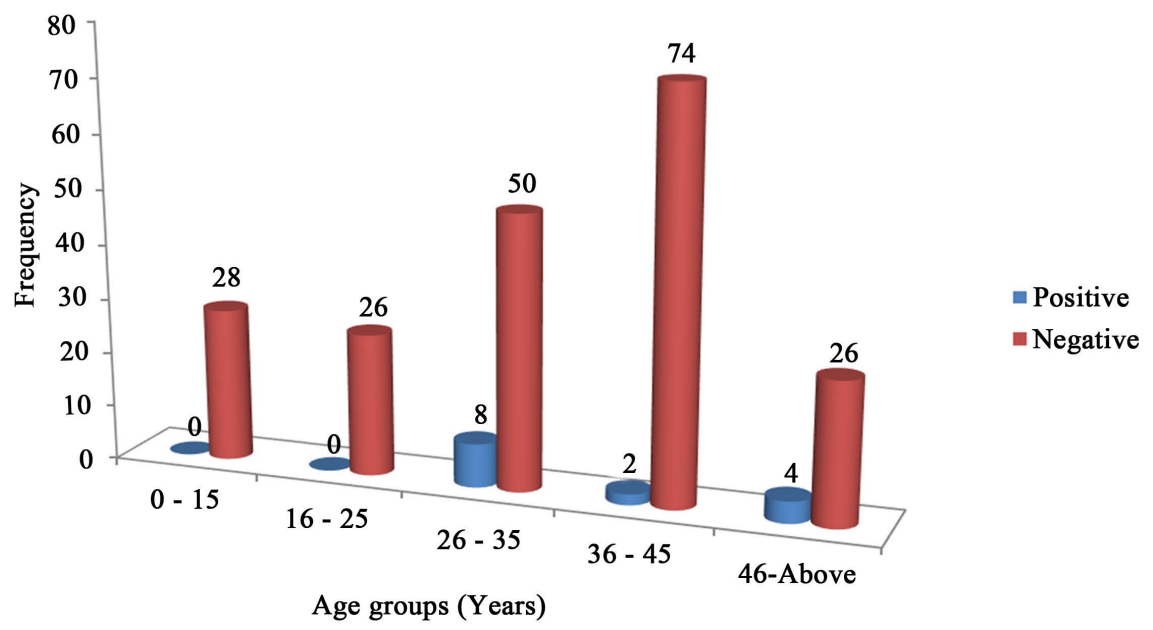

Figure 1. Tuberculosis case distribution by age groups of participants.

The most affected age group was 26 - 35 years with $57 \%$ of positive cases.

\section{Discussions}

\section{Prevalence of Pulmonary Tuberculosis}

The objective of this study was to determine the prevalence of Pulmonary Tu- 
berculosis among adult HIV-positive patients receiving ART services from ART Clinic at Bududa Hospital.

Pulmonary complications have been one of the commonest causes of morbidity and mortality since the advent of AIDS (Acquired Immune Deficiency Syndrome) pandemic. According to an estimate of World Health Organization, TB has become one of the leading causes of death among HIV-infected persons. In Uganda, with national HIV prevalence of 7.3\%, 45,546 TB patients were diagnosed in the year 2010 of which 54\% were HIV-infected [1] [2]. From this study, the prevalence of pulmonary tuberculosis in HIV/AIDs patients was 5.9\% (14/238). People living with HIV are most vulnerable to contracting active TB because of the deficiency of immune response. This study finding showed a lower prevalence compared to global prevalence at $11 \%$. Similar trends have been observed in different settings in Uganda by many authors [2] [6] [7]. These could be explained by the fact that unlike in this study, different approaches were used for TB diagnosis that increased sensitivity hence detecting more positive cases and could also be associated to the control interventions in the area.

The study findings are not in line with the findings from a related study that showed that $17 \%$ of HIV infected persons had tuberculosis co-infection [10]. The difference could be attributed to several diagnostic methods employed like use of chest X-ray, and microscopic examination of sputum for acid fast bacillus hence increasing sensitivity compared to our study that used only smear microscopy affecting sensitivity so we might have missed some cases of tuberculosis hence a lower prevalence.

Despite the low prevalence of HIV-TB co-infection revealed by this study, Tuberculosis attributes to a six-fold to seven-fold increase of viral load in HIV positive population [11] where the infection induces cytokines that enhance the replication of HIV and this drives the patient into full picture of AIDS [12].

This study had 238 participants in which females were more than males with $65.6 \%$ and $34.4 \%$ respectively. The higher number of female participants could have been due to their pronounced health seeking behaviors than males [13].

The prevalence of pulmonary tuberculosis (PTB) based on gender was $4.2 \%$ and $1.61 \%$ in females and males respectively. The gender-related prevalence of PTB observed in this study had a similar trend to findings obtained in similar studies [13] [14] [15].

The age-related prevalence was high among participants who were between 26 - 35 age group constituting a prevalence of $8 / 238(3.4 \%)$. The high prevalence in the age group of 26 - 35 could be attributed to their increased social behaviors like being socially active and attractive to the peers from whom the infections acquired and transmitted. smoking, stress due to poverty and alcoholism predispose this age group to high chances of acquiring the disease [16], The positive cases in 46-above age group could be due to their social behaviors like sharing drinking tubes for local brewed alcohol like "malwa" from which infected cases/people infect others, smoking, and consumption of insufficiently boiled milk, 
poor nutrition status.

These study findings provide the current knowledge about the burden of tuberculosis in HIV/AIDS positive living thus creating awareness to health $\mathrm{Au}$ thorities and policy makers about the infection dangers and is expected to lead to improved efforts in controlling and eradicating of pulmonary tuberculosis among HIV/AID's patients and their community.

All HIV-infected individuals should be tested for tuberculosis prior to the initiation of ART and while on ART in places where this disease is Endemic; where several tests including Gene Xpert, chest X-ray and sputum hot ZN and cultures should be carried out routinely to aid in early detection and treatment to reduce the spread of the disease.

\section{Conclusion}

Tuberculosis remains a health challenge in HIV/AIDS positive people in Bududa district and there is need for early screening of all HIV patients for TB as part of their routine and intensification to follow up TB positive patients.

\section{Recommendations}

These findings suggest that strategies for early HIV diagnosis to increase timely diagnosis of HIV before it is adversely advanced could potentially reduce the occurrence of Tuberculosis in this setting.

In addition, we recommend intensification of public awareness campaign about $\mathrm{TB}$ infection in relation to its transmission and prevention, control and treatment.

\section{Acknowledgements}

I acknowledge Mzee Mutanje Solomon Masudi and the family for the parental, financial and social support. I extend my sincere thanks to participants who voluntarily participated in the study. Furthermore, am grateful to the staffs of Department of Medical Laboratory Sciences, Mbarara University of Science and Technology for technical support and guidance.

\section{Conflicts of Interest}

All authors declare no conflict of interest in the study.

\section{Study Limitations}

The study was analysis of the HIV/TB co-infected patients and the findings might not be generalizable to the whole community.

The study design used could not detect the predictors of the disease among study participants.

In addition, the cultural technique was not performed because of the limited laboratory facilities and funds. 


\section{References}

[1] WHO (2012) Global TB Control Report 2012.

https://apps.who.int/iris/bitstream/handle/10665/75938/9789241564502_eng.pdf?se quence $=1$

[2] World Health Organization (2014) Global Tuberculosis Report. Geneva, Switzerland.

[3] Wynne, A., Richter, S., Banura, L. and Kipp, W. (2014) Challenges in Tuberculosis Care in Western Uganda: Health Care Worker and Patient Perspectives. International Journal of Africa Nursing Sciences, 1, 6-10. https://doi.org/10.1016/j.ijans.2014.05.001

[4] Amuron, B., Levin, J., Birunghi, J., Namara, G., Coutinho, A., Grosskurth, H., et al. (2011) Mortality in an Antiretroviral Therapy Programme in Jinja, South-East Uganda: A Prospective Cohort Study. AIDS Research \& Therapy, 8, 39.

https://doi.org/10.1186/1742-6405-8-39

[5] Moore, D., Liechty, C., Ekwaru, P., Were, W., Mwima, G., Solberg, P., Rutherford, G. and Mermin, J. (2007) Prevalence, Incidence and Mortality Associated with Tuberculosis in HIV-Infected Patients Initiating Antiretroviral Therapy in Rural Uganda. AIDS, 21, 713-719. https://doi.org/10.1097/QAD.0b013e328013f632

[6] Jaganath, D., Zalwango, S., Okware, B., Nsereko, M., Kisingo, H., Malone, L.S., et al. (2013) Tuberculosis Research Unit; Contact Investigation for Active Tuberculosis among Child Contacts in Uganda. Clinical Infectious Diseases, 57, 1685-1692. https://doi.org/10.1093/cid/cit645

[7] Chu, R., Mills, E.J., Beyene, J., Pullenayegum, E., Bakanda, C., Nachega, J.B., et al. (2013) Impact of Tuberculosis on Mortality among HIV-Infected Patients Receiving Antiretroviral Therapy in Uganda: A Prospective Cohort Analysis. AIDS Research and Therapy, 10, Article No. 19. https://doi.org/10.1186/1742-6405-10-19

[8] Agarwal, R., Malhotra, P., Awasthi, A., Kakkar, N. and Gupta, D. (2005) Tuberculous Dilated Cardiomyopathy: An Under-Recognized Entity? BMC Infectious Diseases, 5, Article No. 29. https://doi.org/10.1186/1471-2334-5-29

[9] Cheesbrough, M. (1984) Medical Laboratory Manual for Tropical Countries. Volume Two, Cambridge University Press, Cambridge, 294-299.

[10] Giri, P.A., Deshpande, J.D. and Phalke, D.B. (2013) Prevalence of Pulmonary Tuberculosis among HIV Positive Patients Attending Antiretroviral Therapy Clinic. North American Journal of Medical Sciences, 5, 367-370. https://doi.org/10.4103/1947-2714.114169

[11] Jamadar, N. and Arifulla, M. (2015) HIV, Tuberculosis. Pulmonary Tuberculosis Co-Infection among HIV Infected Patients: A Hospital Based Study from Bijapur, Southern India. Journal of Evolution of Medical and Dental Sciences, 4, 2725-2730. https://doi.org/10.14260/jemds/2015/391

[12] Festenstein, F. and Grange, J.M. (1991) Tuberculosis and the Acquired Immune Deficiency Syndrome. Journal of Applied Bacteriology, 71, 19-30.

[13] Ferlinz, R., Schlegel, J. and Beein, F. (1995) Influence of AIDS on the Epidemiology of Tuberculosis. 449-454.

[14] Umeh, E.U., Ishaleku, D. and Iheukwumere, C.C. (2007) HIV/Tuberculosis Co-Infection among Patients Attending a Referral Chest Clinic in Nasarawa State, Nigeria. Journal of Applied Sciences, 7, 933-935. https://doi.org/10.3923/jas.2007.933.935

[15] Nwobu, G.O., Okodua, M.A. and Tatfeng, Y.M. (2004) Comparative Study of HIV 
Associated Pulmonary Tuberculosis in Chest Clinics From Two Regions of Edo State, Nigeria. Online Journal of Health and Allied Sciences, 3(3).

[16] Okot-Nwang, M., Wabwire-Mangen, F. and Kagezi, V. (1993) Increasing Prevalence of Tuberculosis among Mulago Hospital Admissions, Kampala, Uganda (1985-1989). Tubercle and Lung Disease, 74, 121-125.

https://doi.org/10.1016/0962-8479(93)90038-Y 